\title{
Presence of Zoonotic Helminths in Dog Feces and Soil in the Chapultepec Forest of Mexico City
}

\author{
Ignacio Martínez-Barbabosa*1, Hilda Ortiz-Pérez ${ }^{1}$, José Marcos Aguilar-Venegas, Enrique Gaona², Anna Vitalievna Sokolova- \\ Grinovievkaya ${ }^{3}$, Manuel Gutiérrez-Quiroz ${ }^{4}$, Leticia Araceli Ruiz-González ${ }^{4}$, Ana María Fernández-Presas ${ }^{4}$
}

1*Departamento de Atención a la Salud. Área de Ciencias Básicas. Universidad Autónoma Metropolitana-Xochimilco. Calzada del Hueso 1100 Col. Villa Quietud, Coyoacán, Ciudad de México. México

${ }^{2}$ Departamento de El hombre y su Ambiente. Universidad Autónoma Metropolitana-Xochimilco. Calzada del Hueso 1100 Col. Villa Quietud, Coyoacán, Ciudad de México. México

${ }^{3}$ Departamento de Política y Cultura. Universidad Autónoma Metropolitana-Xochimilco. Calzada del Hueso 1100 Col. Villa Quietud, Coyoacán, Ciudad de México. México

4Departamento de Microbiología y Parasitología. Facultad de Medicina, Universidad Nacional Autónoma de México. Ciudad Universitaria C.P. 04510. Ciudad de México

*Correspondence to: Ignacio Martínez-Barbabosa, Departamento de Atención a la Salud. Área de Ciencias Básicas. Universidad Autónoma Metropolitana-Xochimilco, Calzada del Hueso 1100, Edificio H-009. Col. Villa Quietud, Ciudad de México. C.P. 04960; E-mail: imarti@correo.xoc.uam.mx

Received: November 05, 2017; Accepted: November 16, 2017; Published: November 19, 2017;

\begin{abstract}
Some intestinal dog parasites represent a worldwide problem for human health due to their biotic and zoonotic potential. Metropolitan areas with high concentrations of dogs can be a health risk because of soil contamination with fecal matter. The objective of this study was to determine the presence of zoonotic intestinal parasites in dog feces and soil in the Chapultepec Forest of Mexico City. 210 fecal samples were examined by using the flotation method and direct smear stained with Zhiel Neelsen. Simultaneously, 150 soil samples were studied by means of the Ferreira method. The results were analyzed by using SPSS, version 21, and a chi-square test. The prevalence of fecal parasites was $51.5 \%$. The prevalences of zoonotic parasites were: $T$. canis $34.8 \%$, A. caninum $16.7 \%$, and Cryptosporidium spp. $2.4 \%$. The prevalence of eggs of T. canis in soil samples was $9.3 \%$. Contamination of the forest surface with infectious forms of zoonotic parasites can be a source of infection for visitors, especially children. It is important to implement information and prevention campaigns for zoonotic infection control through health education of the population, in general, and of pet owners, in particular, as well as canine population control.
\end{abstract}

Key words: zoonoses, dogs, environmental contamination, soils, parks.

\section{Introduction}

Dogs are considered to be reservoirs, dissemination agents, and infection sources of a large number of infectious agents $[1,2]$. According to the World Health Organization (WHO), a dog can transmit to a human up to 53 zoonotic diseases caused by viruses, bacteria, fungi, and parasites of medical and veterinary importance. Among these infectious agents, canine intestinal helminths and protozoos stand out. Therefore, dogs are considered to be the main responsible for environmental contamination with fecal matter of forests, parks, gardens, and sidewalks of public spaces in rural and urban areas. [3-5].

Canine intestinal parasites represent a problem for human health due to their biotic and zoonotic potential, since people who live in urban areas such as large cities and megapolises are exposed to canine zoonotic parasite infections. [1,2]. In these areas of human concentration, forests, parks and green areas are an ideal place of recreation for inhabitants, but at the same time a danger of being infected with parasitic zoonoses transmitted by dogs. They represent an increasing risk because of the presence of these animals in recreation sites who are homeless or with an owner and who daily defecate in these public spaces [6,2].

Different epidemiological studies conducted in developed and developing countries in both rural and urban areas report the presence of eggs, larvae, cysts and oocysts of canine intestinal parasites in the samples of contaminated soil obtained from playgrounds, parks, and gardens. Hence, soil is considered a way of transmitting different etiological agents that cause canine zoonotic disease $[7,4,8]$.

Profuse environment fecal contamination with eggs, larvae, cysts and oocysts excreted by infected dogs boosts the transmission of zoonoses. Different parasite infectious forms can survive and remain viable in the environment over a long period of time. Thus, there is an increasing risk of developing cryptosporidiosis or visceral and ocular migrans larva syndromes caused by Toxocara canis or migrans cutaneous larva produced by Ancylostoma caninum and Ancylostoma brasiliensis as well as other diseases produced by helminths transmitted through a direct contact with contaminated soil [4, 9-12]. 
The Chapultepec Forest of Mexico City is an eminent place for family recreation that does not avoid this situation. There live stray dogs that have found in it an ideal place for reproduction, in this way increasing canine population. In addition, many pets are brought to this place who defecate there contaminating the soil, and this a fundamental epidemiological factor in transmitting zoonotic parasites that infect the human population who daily go to this site $[13,5,14]$.

\section{Objective}

This work was carried out in order to determine the presence of eggs of helminths and oocysts of canine zoonotic parasites in the soil and fecal matter samples collected in the Chapultepec Forest, Mexico City.

\section{Material and methods}

\section{Study design}

In the first semester of 2015, descriptive cross-section exploratory sampling was performed with the aim of detecting canine zoonotic enteroparasites in the soil samples and fecal matter collected in the Chapultepec Forest of Mexico City.

\section{Study area}

The Chapultepec Forest is in Mexico City that has $8,851,080$ inhabitants and is located at parallels $19^{\circ} 36^{\prime}$ and $19^{\circ} 03^{\prime}$ north of the equator, and at $98^{\circ} 57^{\prime}$ and $99^{\circ} 22^{\prime}$ west of the Greenwich Meridian, at an altitude 2,240 meters (7,350 ft), with humid temperate climate and average annual temperature $16^{\circ} \mathrm{C}$. The city consists of 16 administrative delegations distributed on the territory of 1,485 square kilometers (573 sq mi). The Chapultepec Forest is an urban park located in the borough (delegación) of Miguel Hidalgo, and is one of the largest of its type in the Western Hemisphere with the land area of 677 hectares. It is divided into three sections. The first one occupies 274 hectares, 182 of which correspond to green areas; there are two lakes. The second section area is 160 hectares. The third section has the total area of 243 hectares, 53.5 hectares of which belong to green areas [15].

\section{Universe and Samples}

\section{Collection of soil samples}

Samples were obtained through a simple random method. In each of the three forest sections, 50 soil samples were collected, preferably before 12 p.m. in shaded areas of family recreation. Initially, the topsoil was removed with a metal shovel. Each sample was obtained from a 10 $\times 20 \times 2 \mathrm{~cm}$ surface area with a soil mass of approximately 200 grams. The obtained samples were deposited in polyethylene bags with the data corresponding to each collection section. All the samples were kept cool at $4^{\circ} \mathrm{C}$ before being analyzed.

The soil analysis was conducted through the Ferreira method. Glass beakers were used to deposit samples separately by homogenizing them with $250 \mathrm{ml}$ of distilled water. The homogenates were sieved using cotton gauze and were collected in Ferreira tubes [16]. The tubes were centrifuged at 2,000 revolutions per minute for three minutes, discarding the floating material. The sediments were resuspended in $35 \mathrm{ml}$ of zinc sulfate at a density of 1: 200; the suspension was homogenized by a second centrifugation at $2000 \mathrm{rpm}$ during five minutes. The floating material was treated through fresh preparations with Lugol solution. The observation was performed by using Carl Zeiss brightfield microscopes at 100 and 400 magnifications. The identification of parasite forms was fulfilled according to their morphology.

\section{Collection of fecal samples}

In three sections of the forest, 210 samples of fecal matter were collected into polyethylene containers with a hermetic lid that were marked with the corresponding section and were placed in a cold net for their transfer to the laboratory of Medical Parasitology of the Metropolitan Autonomous University (Universidad Autónoma Metropolitana), Campus Xochimilco, where they were kept cool at $4^{\circ}$ $\mathrm{C}$ until the moment of their study.

\section{Medical tests}

Each sample was examined macroscopically to detect adult worms and/or cestode proglottids. The identification of oocysts of Cryptosporidium spp. was carried out by a direct fecal spread stained with modified Ziehl Neelsen [17]. Simultaneously, the stool ova and parasite exam was fulfilled through the floatation-concentration technique with zinc sulfate at $1: 18$ [18]; the floating material was treated through fresh preparations with Lugol solution. The observation was performed by using photonic microscopy through Carl Zeiss brightfield microscopes at 100, 400 and 1000 magnifications. The identification of parasitic forms was done according to their staining affinity and morphology. In the case of detecting ancylostomatidae eggs, the morphological identification was carried out by using a stool culture through the Harada-Mori method, and by observing the larva characteristics in order to identify the species.

\section{Statistical analysis}

The sampling information was organized and coded by using SPSS for Windows, version 21.0 (SPSS Inc., Chicago IL, USA). The data obtained from the variables such as the presence of Cryptosporidium spp. and other enteroparasites in three sections of the Chapultepec Forest was used to construct association relationships, graphs, and contingency tables that allowed to have a quantitative description of the collected samples. Chi-square statistical tests and the Fisher exact test were applied to determine the association among the variables with the significance level of $0.05 \%$.

\section{Results}

The study consisted in analyzing 210 fecal samples collected in three forest sections (68 in the first section, 62 in the second one, and 80 in the third one) as well as 50 soil samples from each of three sections. Table 1 shows the general prevalence of $51.5 \%$ of helminth eggs found in 210 fecal samples, the infection by T. canis was present in $34.8 \%$ of them, and by A. caninum in $16.7 \%$. Table 2 displays the general prevalence of helminth eggs that were present in the fecal samples collected in each of three sections of the forest. In the first 
section, the eggs of T. canis prevailed and in the third section the eggs of A. caninum. Table 3 shows that the general analysis of the results of the medical tests in three sections of the forest reveals the presence of helminth eggs in these areas with an estimated $\mathrm{p}$ of $<0.001$. Through the microscopic analysis of 210 fecal samples stained by using the Zhiel Neelsen technique, Cryptosporidium spp, oocysts were spotted in five samples, i.e. in $2.4 \%$ of all samples. Of 150 soil samples analyzed through the Ferreira method, in 14 (9.3\%), T. canis eggs were found, and free-living larvae were observed in 12 samples (7.3\%).

Table 1. General prevelance of helminth eggs in 210 fecal samples obtained in the Capultepec Forest, Mexico

\begin{tabular}{|l|c|c|}
\hline \multicolumn{1}{|c|}{ Eggs } & Frequency & Porcentage \\
\hline & 35 & 16.7 \\
\hline T. canis & 73 & 34.8 \\
\hline Total & 210 & 100.0 \\
\hline Negative & 102 & 51,5 \\
\hline
\end{tabular}

Table 2. Prevalence of canine helminth eggs in 210 feces analyzed by Faust's method in three section of the Chapultepec Forest, Mexico City

\begin{tabular}{|l|c|c|c|c|}
\hline \multirow{2}{*}{ Helminth eggs } & \multicolumn{3}{|c|}{ Section } & \multirow{2}{*}{ Total } \\
\cline { 2 - 4 } & $\mathbf{1}$ & $\mathbf{2}$ & $\mathbf{3}$ & \\
\hline A. caninum & 10 & 10 & 15 & 35 \\
\hline T. canis & 32 & 28 & 13 & 73 \\
\hline Negative & 26 & 24 & 52 & 102 \\
\hline Total & 68 & 62 & 80 & 210 \\
\hline
\end{tabular}

Table 3. General prevalence of canine helminth eggs in 210 feces analyzed by Faust's method in three section of the Chapultepec Forest, Mexico City

\begin{tabular}{|l|c|c|c|c|}
\hline \multicolumn{2}{|l|}{ Negative } & \multicolumn{2}{|l|}{ Faust's method } & \multirow{2}{*}{ Total } \\
\cline { 3 - 5 } \multicolumn{2}{|c|}{} & Negative & Positive & \\
\hline \multirow{3}{*}{ Section } & 1 & 26 & 42 & 68 \\
\cline { 2 - 5 } & 2 & 24 & 38 & 62 \\
\cline { 2 - 5 } & 3 & 52 & 28 & 80 \\
\hline Total & 102 & 108 & 210 \\
\hline
\end{tabular}

$* \mathrm{p}<0.001$

\section{Discussion}

The Chapultepec Forest, the oldest urban park in the Americas and one of the oldest in the world, has been visited by 15 million people annually and by 200,000 every weekend. It is one of the largest urban parks in the world, on a par with Central Park in NY, Hyde Park in London, or Le Bois de Boulogne in Paris. The forest green areas are a favorite place for city resident recreation. However, a large number of homeless dogs that live there present a danger of physical aggression toward the visitors and also a risk to them of getting different zoonotic diseases such as rabies, syphilis; the stray canine population as well as parasitized dogs that accompany visitors indiscriminately contaminate the soil with helminth eggs and zoonotic protozoan cysts that are present in their feces, and in this way the contaminated soil represents an important source of infection and a significant impact on public health [6,7]. The species of zoonotic nematodes identified in this study were T. canis and A. caninum. The first type is considered to be the main etiological agent of toxocariasis, a parasitic zoonosis that causes significant morbidity and a serious public health problem in the world, mainly in developing countries [7]. The morbidity of human toxocariasis is related to the following factors: a close contact of humans with dogs and cats, an increase of the dog and cat population, a shortage of sanitary control of the fecal matter evacuated by these animals both in public sites and at home, scarce knowledge that people have of this zoonosis, and, especially, a lack of a timely diagnosis that could prevent the development and evolution of the disease before it could produce cases as serious as loss of vision or death [12].

In this study, the rate of soil contamination with this zoonosis in the Chapultepec Forest was 9.3\%. Similar studies of soil contamination with $T$. canis eggs in different countries reported frequencies similar to those obtained by us, for example: $6.8 \%$ in Poland [14] $16.4 \%$ in Madrid, Spain [16]; 6.6\% in Italy [20], and 9.2\% in Chile [21]. However, some developing countries have reported frequencies that are higher than those obtained in our study, such as $20.3 \%$ in Iran [10], or the one in a study of 25 state parks in Presidente Prudente, Brazil where T. canis was reported in $96.6 \%$ of sampled parks [22].

From the epidemiological point of view, the biotic potential of T. canis is enormous because a female can produce up to 200,000 eggs per day. The Pan American Health Organization (PAHO) has estimated that 1 gram of dog fecal matter can contain up to 15,000 Toxocara eggs that are deposited in the ground by walking people, rain, wind or vectors, $[23,24]$. The thick layer of Toxocara eggs makes them resistant to cold and environmental changes; therefore, under adequate humidity and temperature conditions, they can survive in the earth surface for several years. Thus, despite the fact that the soil may appear to be clean because the feces were collected by the health personnel or because the fecal material has disintegrated and there is no odor, it can be contaminated with microscopic infectious forms of parasites.

Soil contaminated with $T$. canis larvae is the main source of infection for humans. In humans as well as in dogs, the infecting form is a larval egg. T. canis larval eggs affect different organs in both humans and dogs; however, adult parasites develop only in dogs. Thus, people who visit recreation sites with contaminated soil are exposed to infection. The most vulnerable people are those under eight years old because their play activities put them in greater contact with soil. Infection in children is caused mainly by geophagy or ingestion of $T$. canis infectious larvae from contaminated soil, or ingestion of larval eggs that are present in dogs' hair [25-28]. In developed countries, despite the fact that the prevalence of parasitic diseases is usually low there, toxocariasis is the most common helminth disease [3, 29].

The ingested eggs hatch in the digestive tract, and the larvae enter the intestinal mucosa, then reach mesenteric vessels and spread to different organs and tissues where the host's response traps them by producing granulomas, whose degree of disease will be in direct proportion to the number of infected ingested larval eggs. In the clinical form of the disease known as visceral migrant larva, the symptoms are nonspecific and consist of abdominal pain, anorexia, malaise, behavioral disorders, cervical adenitis, hepatomegaly, pain in extremities, and fever. Children under 5 years old are the most affected, and the main risk factors in this population are geophagy and 
close contact with dogs. The most severe form of the disease occurs in the eyes, where it produces ocular migrant larva syndrome (LMO), [30]. It has been reported that a single larva can cause unilateral blindness. Vision loss occurs because of the acute inflammatory reaction of the retina and optic nerve. The risk of being in contact with soils contaminated with $T$. canis eggs is very severe because a case of congenital ocular toxocariasis in a newborn has been recently documented [31].

In the case of A. caninum, human infection is caused by penetration of a filariform larva into the skin, but as it is unable to invade deeper tissues, it produces a skin lesion that is several centimeters long and is very itchy due to carving a tunnel in the epidermis known as migratory cutaneous larva or verminous creeping dermatitis $[11,32,33]$.

The prevalence rates of this helminth reported by some authors of similar studies vary from $4.2 \%$ in Chile [21] 6.8\% in Italy [20], 13.5\% in Brazil [34]. A clear example of the severity of soil contamination with geohelminths of canine origin is beach sand in Brazil where the presence of A. caninum in $82.5 \%$ of its samples was reported [35].

The detection of Cryptosporidium spp. in fecal samples of examined dogs supports the idea that infected canines are a potential source of human infection [36]. Dog infection with Cryptosporidium spp. reported in this study is less than that obtained in the studies with similar characteristics performed in France 2.6\% [37], Sao Paulo, Brazil, 3.1\% [38], and is similar to infection reported in Zaragoza, Spain, 5.5\% [39], Egypto 5.4\% [40] Niagara, Canada, 7.4\% [41] Prague, Czech Republic, 9.3\%; Japan, 7.2\% [42], and the Netherlands, 8.7\% [25]. However, the infection data obtained in the present study were less than $40 \%$ reported in the city of Campos dos Goytacases, Brazil [43].

The discrepancy in the above-mentioned results is due to different factors such as climatic conditions of the place of study, soil characteristics, soil contamination degree, sociocultural factors, and laboratory procedures.

The presence of Cryptosporidium spp. in infected animal feces plays an important role in transmitting these microorganisms, since dogs constantly eliminate a small number of sporulated oocysts that is, however, sufficient to infect humans and other animals. The problem gets worse if we consider the concatenation of some biological and climatic factors inherent to the parasite such as low dosage of oocysts (10 oocysts) required to develop infection [44]. The resistance of oocysts to environmental changes as well as to the conventional water treatment becomes epidemiologically important given that forest and garden irrigation is generally performed with water which contributes to soil contamination and oocyst dissemination and viability. In damp environments such as public parks, $C$. parvum oocysts can remain viable for 2-6 months $[45,40,11]$.

Another factor that contributes to dogs' infection with Cryptosporidum is the biological cycle of the latter that consists of three autoinfectious reproductive phases as well as the production of thin-walled oocysts that embed themselves deeply in the host intestine originating chronic infections without a need of new infections. As a result of this autoinfection, during defecation a dog releases constant infectious oocysts that contaminate soil as in the case of experimentally infected dogs who had up to 10,000 oocysts per one gram of their fecal material [46].

It is necessary to advise people with high risk such as immunocompromised or of extreme ages of the life and who visit parks to maximize their hygienic habits as, for example, washing hands after touching the hair of the dogs that go to these places regardless of whether they are stray or with an owner [28].

Despite a small number of samples, the rates of infection with zoonotic enteroparasites detected in the present work are important from the epidemiological and public health point of view because of soil contamination by enteric zoonotic species of parasitized animals that live or are brought to parks with ecological characteristics similar to those of the Chapultepec Forest in Mexico City [47-49].

With the aim of preventing zoonotic diseases transmitted by dogs, it is vital to implement actions such as daily collection of fecal matter in recreation areas; the control of synanthropic flies that participate in the dissemination of different zoonoses [23, 24], the direct participation of dog owners that visit the forest in collecting and eliminating stool evacuated by their pets; promotion of semi-annual de-worming; and scheduled sterilization in order to contribute to the reduction of street canine population, since many puppies are released to streets at an early age. Implementing these actions, undoubtedly, will help to get within a short time healthier environment for the inhabitants of Mexico City [50].

Finally, we believe that it is necessary to conduct more studies in order to detect the presence of intestinal parasites in animals as family members and, thereby, to evaluate the impact that these agents have on human health. In addition, such studies will provide the basis for recommending control measures in health programs.

\section{Conclusions}

The results of the study highlight the risk of transmitting canine zoonotic parasitosis to the human population, especially children, during their public park visits.

The presence of canine fecal matter in urban area soil is the main source of enteric pathogen infection of stray and domestic animals as well as humans. Preventing soil contamination is the most important way in the prevention of zoonoses transmitted by dogs together with other actions such as social responsibility of a strict control of canine fecal matter elimination not only in the Chapultepec Forest, but also in Mexico City streets, gardens and parks that include dog owners' participation and health-authorities' participation in the case of stray dogs. In addition to this, it is crucial to encourage quarterly de-worming of captured dogs, especially those under one-year-old. Through these simple measures, in a short term it would be possible to reduce soil contamination and minimize human and animal health risk.

\section{References}

1. Abu Samra N, Jori F, Cacciò SM, Frean J, Poonsamy B, et al (2016) Cryptosporidium genotypes in children and calves living at the wildlife or livestock interface of the Kruger National Park, South Africa. Onderstepoort J Vet Res 83: e1-1e7. [crossref] 
2. Felsmann M, Michalski M, Felsmann M, Sokól R, Szarek J, Strzyewska-Worotynka E (2017) Invasive forms of canine endoparasites as a potential threat to public health - A review own studies. Ann Agric Environ Med 24: 245-249.

3. Szwabe K, Blaszkowska J2 (2017) Stray dogs and cats as potential sources of soil contamination with zoonotic parasites. Ann Agric Environ Med 24: 39-43. [crossref]

4. Studznska MB, Demkowska-Kutrzepa M, Borecka A, Meisner M, Tomczuk K, et al. (2017) Variation in the Rate of Infestation of Dogs with Zoonotic Nematodes and the Contamination of Soil in Different Environments. Int J Environt Res Public Health 14: Pii: E1003

5. Feng Y, Xiao L (2017) Molecular Epidemiology of Cryptosporidiosis in China. Front Microbiol 8: 1701. [crossref]

6. Fletcher SM, Stark D, Harkness J, Ellis J (2012) Enteric protozoa in the developed world: a public health perspective. Clin Microbiol Rev 25: 420-449. [crossref]

7. Anh NT, Thuy DT, Hoan DH, Hop NT, Dung DT (2016) Levels of Toxocara infect ions in dogs and cats from urban Vietnam together with associated risk factors for transmission. Helminthol 90: 508-10.

8. Otero D, Alho AM, Nijsse R, Roelfsema J, Overgaauw P, et al. (2017) Environmental contamination with Toxocara spp. Eggs in public parks and sandpits of Greater Lisbon, Portugal. J Infect Health pii: S1876-0341(17)30134.

9. Martínez-Barbabosa I, Gutiérrez CEM, Aguilar VJM, Pimienta LJJ, Shea M (2011) Frecuencia de geohelmintos en canes domiciliados en siete delegaciones de la Ciudad de México. Vet Méx 42: 83-91.

10. Berenji F, Movahedi Rudy AG, Fata A, Tavassoli M, Mousavi Bazaz M, et al. (2015) Soil Contamination with Toxocara Spp. Eggs in Public Parks of Mashhad and Khaf, North East of Iran. Iran J Parasitol 10: 286-289. [crossref]

11. Díaz-Anaya AM, Pulido-Medellín MO, Giraldo-Forero JC (2015) Nematodes with zoonotic potential in parks of the city of Tunja, Colombia. Salud Publica Mex 57: $170-6$

12. Lötsch F, Vingerling R, Spijker R, Grobusch MP (2017) Toxocariasis in humans in Africa - A systematic review. Travel Med Infect Dis. [crossref]

13. Zanzani SA, Di Cerbo AR, Gazzonis AL, Genchi M, Rinaldi L, et al. (2014) Canine fecal contamination in a metropolitan area (Milan, Nothh-western Italy): prevalence of intestinal parasites and evaluation of health risk. Scientific World Jounal 2014: 132.361 .

14. Blaszkowska J, Góraiska K, Wojcik A, Kumatowski P, Szwabe K (2015) Presence of Toxocara spp. eggs in children's recreation areas with varing degrees of access for animals. Ann Agric Environ Med 22: 23-7.

15. INEGI (2015) Instituto Nacional de Geografía Estadística e Informática Centro de Población y Vivienda.

16. Dado D, Izquierdo F, Vera O, Montoya A, Mateo M, et al. (2012) Detection of zoonotic intestinal parasites in public parks of Spain. Potential epidemiological role of microsporidia. Zoonoses Public Health 59: 23-8.

17. Aquino MJM, Vargas SGB, López MB, Neri SE, Bernal RR (2012) Comparación de dos nuevas técnicas de sedimentación y métodos convencionales para la recuperación de parásitos intestinales. Rev Latinoamer Patol Clin 59: 233-242.

18. Henriksen SA, Pohlenz JF (1981) Staining of cryptosporidia by a modified ZiehlNeelsen technique. Acta Vet Scand 22: 594-596. [crossref]

19. Faust EC, DÁntoni JS, Odom V, Miller NJ, Pares C, Sawitzl E (1938) A critical study of clinical laboratory techniques for the diagnosis of protozoans cysts and helminth eggs in feces. Am J Trop Medicine 18: 169-193.

20. Paoletti B, Traversa D, Iorio R, De Berardinis A, Bartolini R, et al. (2015) Zoonotic parasites in feces and fur of stray and private dogs from Italy. Parasitol Res 114: 2135-2141. [crossref]

21. Luzio A, Belmar P, Troncoso I, Luzio P, Jara A (2015) Fernandez I. Parasites of zoonotic importance in dogs' feces collected in parks and public squares of the city of Los Angeles, BÍo-Bío, Chile. Rev Chilena Infectol 32: 403-7.

22. Santarém VA, Pereira VC, Alegre BC (2012) Contamination of public parks in Presidente Prudente (São Paulo, Brazil) by Toxocara spp. eggs. Rev Bras Parasitol Vet 21: 323-325. [crossref]

23. Racewicz M, Kruminis- $\AA$ ozowska W, Gabre RM, Stå̊,czak J (2009) [The occurrence of Cryptosporidium spp. in synanthropic flies in urban and rural environments]. Wiad Parazytol 55: 231-236. [crossref]

24. Kebede N (2011) Cryptosporidium recovered from Musca domestica, Musca sorbens and mango juice accessed by synanthropic flies in Bahirdar, Etiopia. Zoonoses Public Health 58: 69-75. MOSCAS

25. Overgaauw PA, van Zutphen L, Hoek D, Yaya FO, Roelfsema J, et al. (2009) Zoonotic parasites in fecal samples and fur from dogs and cats in The Netherlands. Vet Parasitol 163: 115-122. [crossref]

26. Fetene T, Worku N, Huruy K, Lötsch F, Vingerling R, et al. (2017) Toxocariasis in humans in Africa - A systematic review. Travel Med Infect Dis pii: S1477-8939.

27. Tavassoli M, Javadi S, Firozi R, Rezaei F, Khezri A, et al. (2012) Hair Contamination of Sheepdog and Pet Dogs with Toxocara canis Eggs. Iran J Parasitol 7: 110-115. [crossref]

28. Merigueti et al. (2017) YFFB, Santarém VA, Ramirez LM, da Silva Batista Batista A, da Costa Beserra LV, Nuci AL, de Paula Esposte TM. Protective and factors associated with the presence of Toxocara spp. in eggs in dog hair. Vet Parasitol 244: 39-43.

29. Inpankaew T, Jiyipong T, Sunanta C, Kengradomkii C, Pinyopanuwat N, et al (2017) Prevalence and molecular characterization of bovine Cryptosporidium from dairy cows in Northern Thailand. Acta Parasitol 62: 772-774

30. Chen Q, Gu J, Jiang R, et al. (2017) Role of ultrasound biomicroscopy in diagnosis of ocular toxocariasis. Br J Ophthalmol [crossref]

31. Maffrand R, Avila-Vázquez M, Princich D, Alasia P (2006) [Congenital ocular toxocariasis in a premature neonate]. An Pediatr (Barc) 64: 599-600. [crossref]

32. Veraldi S, Cuka E, Pontini P, Vaira F (2017) Bullous cutaneous larva migrans: case series and review of atypical clinical presentations. G Ital Dermatol Venereol 152: 516-519

33. Manikat R, Kannangara S2 (2017) Cutaneous Larva Migrans. J Glob Infect Dis 9: 125. [crossref]

34. Moura MQ, Jeske S, Vieira JN, Corrêa TG, Berne ME, et al. (2013) Frequency of geohelminths in public squares in Pelotas, RS, Brazil. Rev Bras Parasitol Vet 22: 175-178. [crossref]

35. Rocha S, Pinto RM, Floriano AP, Teixeria LH, Bassili B, et al. (2011) Environmental analyses of the parasitic profile found in the Sandy soil from the Santos municipality beaches, SP, Brazil. Rev Inst Med Trop Sao Paulo 2011 Sep-Oct: 5385): 277-81

36. Gil H, Cano L, de Lucio A, Bailo B, de Mingo MH, Cardona GA, et al. (2017) Detección and molecular diversity of Giardia duodenalis and Cryptosporidium spp. In Sheltered dogs and cats in Northern Spain. Infect General Evol 50: 62-69

37. Osaman M, Bories J, El Safadi D, Poirel MT, Gantois N, et al. (2015) Prevalence and genetic diversity of the intestinal parasites Blastocystis sp. And Cryptosporidium spp. In household dogs in France and evaluation of zoonotic transmission risk. Vet Parasitol 214: 167-170.

38. Katagiri A, TC Oliveira-Sequeira (2008) Prevalence of dog intestinal parasites and risk perception of zoonotic infection by dog owners in Sao Paulo State, Brazil. Zoonoses Public Health 55: 406-413.

39. de Lucio A, Bailo B, Aguilera M, Cardona GA, Fernández-Crespo JC, et al. (2017) No molecular epidemiological evidence supporting household transmission of zoonotic Giardia duodenalis and Cryptosporidium spp. From pet dogs and cats in the province of Álava, Northern Spain. Acta Trop 170: 48-56.

40. Awadallah MA, Salem LM (2015) Zoonotic enteric parasites transmitted from dogs in Egypt with special concern to Toxocara canis infection. Vet World 8: 946-957. [crossref]

41. Shukla R, Giraldo P, Kraliz A, Finnigan M, AL Sanchez (2006) Cryptosporidium spp. And other zoonotic enteric parasites in a sample of domestic dogs and cats in the Niagara region of Ontario. Can Vet J 47: 1179-84.

42. Itoh N, Oohashi Y, Ichikawa-Seki M, Itagaki T, Ito Y, et al. (2014) Molecular detection and characterization of Cryptosporidium species in household dogs, pet shop puppies, and dogs kept in a school of veterinary nursing in Japan. Vet Parasitol 200: $284-8$.

43. Ederil BB, MF Rodrigues, CB Carvalho (2005) Oocysts of the genus Cryptosporidium in domiciliated dogs from the city of Campos dos Goytacases, the State of Rio de Janeiro. Rev Bras Parasitol Vet 14: 129-31.

44. de Graaf DC, Vanopdenbosch E, Ortega-Mora LM, Abbassi H, Peeters JE (1999) A review of the importance of cryptosporidiosis in farm animals. Int J Parasitol 29: 1269-1287. [crossref]

45. Pereira VJ, Marquez R, Marques M, Benoliel MJ, Barreto Crespo MT (2013) Free chlorine inactivation of fungi in drinking water sources. Water Res 47: 517-23.

46. Lloyd S, J Smith (1997) Pattern of Cryptosporidium parvum oocyst excretion by experimentally infected dogs. Int J Parasitol 27: 799-801.

47. Avcioglu H, Balkaya I (2011) The relationship of public park accessibility to dogs to the presence of Toxocara species ova in the soil. Vector Borne Zoonotic Dis 11: 177-180. [crossref]

48. Blaszkowska J, Wojcik A, Kurnatowski P, Szwabe K (2013) Geohelminth egg contamination of children's play areas in the city of Lodz (Poland). Vet Parasitol 192: 228-233. [crossref]

49. Blaszkowska J, Góraiska K, Wojcik A, Kumatowski P, Szwabe K. Presence of Toxocara spp. eggs in children's recreation areas with varing degrees of access for animals. Ann Agric Environ Med 22: 23-7.

50. Hackett T, MR Lappin (2003) Prevalence of enteric pathogens in dogs of northcentral Colorado. J Am Anim Hosp Assoc 39, 52-6.

\section{Citation:}

Ignacio Martínez-Barbabosa, Hilda Ortiz Pérez, José Marcos Aguilar Venegas, Enrique Gaona, Anna Vitalievna Sokolova Grinovievkaya, Manuel Gutiérrez Quiroz, Leticia Araceli Ruiz González, Ana María Fernández Presas (2017) Presence of Zoonotic Helminths in Dog Feces and Soil in the Chapultepec Forest of Mexico City. Integr J Vet Biosci Volume 1(2): 1-5 